\title{
Uterine rupture: a retrospective analysis of causes, complications and management outcomes at Muhimbili National Hospital in Dar es Salaam, Tanzania
}

\author{
HUSSEIN L. KIDANTO ${ }^{1,2^{*}}$, IPYANA MWAMPAGATWA ${ }^{3}$ and JOS VAN ROOSMALEN ${ }^{4}$ \\ ${ }^{1}$ Department of Obstetrics and Gynaecology, Muhimbili National Hospital, Dar es Salaam, Tanzania \\ ${ }^{2}$ Department of Obstetrics and Gynaecology, Muhimbili University of Health and Allied Sciences, Dar es \\ Salaam, Tanzania \\ ${ }^{3}$ Department of Obstetrics and Gynaecology, University of Dodoma, Tanzania \\ ${ }^{4}$ Department of Obstetrics Leiden University Medical Centre, and Section of Health Care and Culture, VU \\ University Medical Centre, Amsterdam, The Netherlands
}

\begin{abstract}
Rupture of the gravid uterus is an obstetric catastrophe that is associated with complications that include massive blood loss, hysterectomy, and damage to the genitourinary tract. It is a serious complication that is associated with high maternal and perinatal morbidity and mortality. We conducted a retrospective review of case notes (from 2003 to 2009) to determine the incidence, causes, complications and foetal/maternal outcome among women with a diagnosis of ruptured uterus at Muhimbili National Hospital (MNH) in Dar es Salaam Tanzania. Case notes with diagnosis of ruptured uterus were retrieved from the records department and information on maternal demographic characteristics, surgical intervention, maternal and perinatal outcome were collected using a check list. Where information was inadequate it was sought from the obstetric database. Obtained data was cleaned and analyzed using PASW statistics 18 software. Out of 72,570 deliveries 163 cases of ruptured uterus were recorded in seven years, making an incidence of 2.25 per 1000 births. Most ruptures (38\%) resulted from neglected obstructed labour and scared uterus (33.6\%). Major obstetric haemorrhage $(>1500 \mathrm{ml})$ was the most frequently encountered complication followed by sepsis. Subtotal hysterectomy was the most common (73.6\%) surgical intervention. Maternal and perinatal case fatality rates were $12.9 \%$, and $96.3 \%$ respectively. Ruptured uterus contributed to $6.6 \%$ of all maternal deaths. These findings underscores the need for proper monitoring of labour both in the referring facilities and at $\mathrm{MNH}$ and improvement of comprehensive emergence obstetric care at all levels of health care to avoid unnecessary delays in care.
\end{abstract}

Keywords: obstructed labour, uterine rupture, hysterectomy, maternal mortality, Tanzania

\section{Introduction}

Rupture of the unscarred uterus is much more frequent in low-income countries due to obstructed labour, and is an important cause of direct maternal death (Mishra et al., 2006). Major obstetric haemorrhage is the most frequent cause of serious maternal morbidity and is one of the most important causes of maternal mortality (Hofmeyr et al., 2005).

Several studies from Africa and Asia, shows that about $75 \%$ of cases of uterine rupture occurred in women with an unscarred uterus, with obstructed labour being the most common cause (Amanel \& Mengiste, 2002; Padhye, 2005). Case fatality rates in ruptured uterus range between $1 \%$ and $13 \%$ and perinatal mortality rate between $74 \%$ and 92\% (Ezechi et al., 2004). In high income countries rupture of a scared uterus is more common and the result is less dramatic than in the non scared uterus (Guise et al., 2004; Kaczmarczyk et al., 2007). A high incidence of uterine rupture in any setting is an indicator

\footnotetext{
* Correspondence: Hussein L. Kidanto; E-mail: hkidanto@yahoo.co.uk
} 
of poor obstetric care. This study was conducted to establish the incidence of uterine rupture as well as to identify causes, complications and management outcomes at a teaching hospital in Tanzania.

\section{Materials and Methods}

\section{Study area}

The study was carried out in the labour ward of the Muhimbili National Hospital (MNH), a teaching hospital for Muhimbili University of Health Sciences in Dar es Salaam, Tanzania. $\mathrm{MNH}$ is one of four large consultant hospitals in Tanzania. The hospital serves as a referral centre for the city of Dar es Salaam and the neighbouring regions. Annual number of deliveries is about 10,000 , corresponding to about 30 deliveries per day, out of which $80 \%$ are low-risk deliveries.

\section{Study design and data collection}

This was a retrospective review of case notes. Case notes for all women with the diagnosis of uterine rupture from January $1^{\text {st }} 2003$ to December $31^{\text {st }} 2009$ were traced from the records department and reviewed. Identification of all cases was done through the electronic obstetric database and obstetrics theatre register before the case notes were retrieved.

For each case, information was abstracted on the date of birth, antenatal care attendance, source of admission, place of diagnosis, maternal age, parity, birth weight, sex and vital status of the baby at birth (Apgar score at 1 and 5 minutes), others were physical examination findings during admission, causes of uterine rupture, intra-operative findings and type of surgical intervention. A check list was used to make sure that all the required information was captured. Whenever data was deficient it was traced to the obstetric database.

\section{Data analysis}

Data was entered using EpiInfo 6 software, cleaned and analyzed with PAWS 18 statistics package. Uterine rupture was defined as the occurrence of clinical symptoms (abdominal pain, abnormal foetal heart rate pattern, acute loss of contractions, vaginal blood loss) leading to an emergency caesarean delivery, at which the presumed diagnosis of uterine rupture was confirmed; or peripartum hysterectomy or laparotomy was done for uterine rupture. Cases of scar dehiscence found during elective caesarean section without proceeding clinical symptoms were not included. Women without a known previous caesarean section, previous uterine rupture, myomectomy or perforation were considered having an unscarred uterus.

\section{Ethical considerations}

Ethical clearance for this study was granted by the ethics and publication committee of Muhimbili University of Health and Allied Sciences (MUHAS) and permission to collect data was granted by $\mathrm{MNH}$ administration. Names and other identity of clients were not disclosed to keep confidentiality. 


\section{Results}

During the study period, 72,570 deliveries occurred at Muhimbili National Hospital. A total of 163 cases of uterine rupture were recorded. Of these, $55(33.6 \%)$ had a uterine scar. The incidence of uterine rupture was 2.25 per 1000 deliveries. Detailed information of all cases $(100 \%)$ was received from case notes and the obstetric database.

More than $80 \%$ of all cases were in their first to fourth parity (Table 1). All patients attended antenatal clinic at least once. Three quarters $(74.8 \%)$ of the patients were referred from other health facilities of whom $(21.5 \%)$ were correctly diagnosed to have uterine rupture at the referring institution.

Table 1: Characteristics of the study population

\begin{tabular}{lllllll}
\hline Characteristics & Response & $\begin{array}{l}\text { All } \\
\mathbf{( N = 7 2 , 5 7 0 )}\end{array}$ & deliveries & $\mathbf{\%}$ & RU (N=163) & $\mathbf{\%}$ \\
\hline Maternal age groups & $<20$ & 8434 & 11.6 & 4 & 2.5 \\
& $20-29$ & 40773 & 56.2 & 78 & 47.9 \\
& $30-39$ & 20995 & 28.9 & 70 & 42.9 \\
Parity & $\geq 40$ & 2368 & 3.3 & 11 & 6.7 \\
& 0 & 28808 & 39.7 & 14 & 8.6 \\
Number of ANC visits & 0 & 58457 & 53.0 & 114 & 69.9 \\
Birth weight & $1-3$ & 5305 & 7.3 & 35 & 21.5 \\
& At least once & 72509 & 0.9 & 0 & 0 \\
& $<2500$ & 12323 & 99.1 & 163 & 100 \\
& $2500-3499$ & 43241 & 17 & 13 & 8 \\
& $3500-4000$ & 14309 & 59.6 & 76 & 46.6 \\
& $>4000$ & 2697 & 16.7 & 61 & 37.4 \\
\hline
\end{tabular}

RU=Ruptured uterus

Obstructed labour was the leading cause of ruptured uterus $(38 \%)$, followed by scared uterus (33.6) [previous caesarean (29.4\%), repaired ruptured uterus $(2.4 \%)$, previous myomectomy $(1.8 \%)]$ (Table 2$)$. Others were use of both misoprostol and oxytocin $(12.3 \%)$.

Table 2: Causes of ruptured uterus at Muhimbili National Hospital

\begin{tabular}{l|l|l}
\hline Causes & Number of ruptured uterus, $\mathbf{N = 1 6 3}$ & Percentage \\
\hline Obstructed labour & 62 & 38 \\
Previous caesarean section & 48 & 29.4 \\
Misoprostol use alone & 14 & 8.6 \\
Oxytocin use alone & 12 & 7.4 \\
Use of both Misoprostol /oxytocin & 20 & 12.3 \\
Previous RU & 4 & 2.4 \\
Previous myomectomy & 3 & 1.8 \\
\hline
\end{tabular}

There were 21 maternal deaths and 157 perinatal deaths giving case fatality rates of $12.9 \%$ and $96.3 \%$, respectively (Table 3 and 4). Major obstetric haemorrhage was the commonest maternal complication. Other maternal complications were all patients had blood transfusion, sepsis vesicovaginal fistula and minor bladder injuries ((Table 4). 
Table 3: Incidence and case fatality rate (CFR) of ruptured uterus from 2003-2009

\begin{tabular}{lllllllll}
\hline Year & $\begin{array}{l}\text { Total } \\
\text { deliveries } \\
\text { per year }\end{array}$ & $\begin{array}{l}\text { CS } \\
\text { rate } \\
\mathbf{( \% )}\end{array}$ & $\begin{array}{l}\text { RU } \\
\text { cases }\end{array}$ & $\begin{array}{l}\text { Incidence } \\
\text { of RU }\end{array}$ & $\begin{array}{l}\text { Cases } \\
\text { died } \\
\text { from } \\
\text { RU }\end{array}$ & $\begin{array}{l}\text { Total } \\
\text { maternal } \\
\text { deaths }\end{array}$ & CFR (\%) & $\begin{array}{l}\text { Contribution } \\
\text { of RU } \\
\text { maternal } \\
\text { deaths (\%) }\end{array}$ \\
\hline $\mathbf{2 0 0 3}$ & 12242 & 25.9 & 29 & $1: 237$ & 3 & 58 & 10.3 & 5.1 \\
$\mathbf{2 0 0 4}$ & 11531 & 31.6 & 30 & $1: 260$ & 4 & 68 & 13.3 & 5.9 \\
$\mathbf{2 0 0 5}$ & 11362 & 27.1 & 17 & $1: 150$ & 2 & 58 & 11.7 & 3.4 \\
$\mathbf{2 0 0 6}$ & 10214 & 30.8 & 19 & $1: 186$ & 3 & 25 & 15.8 & 12 \\
$\mathbf{2 0 0 7}$ & 9729 & 36.9 & 34 & $1: 349$ & 2 & 36 & 5.88 & 5.5 \\
$\mathbf{2 0 0 8}$ & 8000 & 44.1 & 17 & $1: 212$ & 3 & 36 & 17.6 & 8.3 \\
$\mathbf{2 0 0 9}$ & 9492 & 46.6 & 17 & $1: 179$ & 4 & 39 & 23.5 & 10.2 \\
Total & 72570 & 33.9 & 163 & 1.225 & 21 & 320 & 12.9 & 6.6 \\
\hline
\end{tabular}

$\mathrm{CS}=$ caesarean section, $\mathrm{RU}=$ Ruptured uterus

Table 4: Maternal/foetal outcomes, place of diagnosis, source of admission, surgical intervention and surgeon

\begin{tabular}{|c|c|c|c|}
\hline Variable & Outcome & Frequency (n) & Percentage \\
\hline \multirow{2}{*}{ Foetal outcome } & Perinatal deaths & 157 & 96.3 \\
\hline & Survived & 6 & 3.7 \\
\hline \multirow[t]{5}{*}{ Maternal complications } & Sepsis & 27 & 17.5 \\
\hline & VVF & 14 & 6.2 \\
\hline & Minor bladder injuries & 20 & 3.3 \\
\hline & Major obstetric haemorrhage (>1500 ml) & 56 & 34.4 \\
\hline & Need for blood transfusion & 163 & 100 \\
\hline \multirow[t]{9}{*}{ Place of diagnosis } & At referring health facility & & \\
\hline & At MNH labour ward & 35 & 21.5 \\
\hline & Intra-operatively & 112 & 68.7 \\
\hline & Missed information & 13 & 8.0 \\
\hline & Source of admission & 3 & 1.8 \\
\hline & Home & & \\
\hline & Hospital transfer(referrals) & 41 & 25.2 \\
\hline & MNH & 110 & 67.5 \\
\hline & Others(Unknown) & 4 & 2.4 \\
\hline \multirow[t]{2}{*}{ Surgical findings } & Complete uterine rupture & 135 & 83 \\
\hline & Incomplete uterine rupture & 28 & 17 \\
\hline \multirow[t]{4}{*}{ Surgical intervention } & Total abdominal hysterectomy & 3 & 1.8 \\
\hline & Subtotal hysterectomy & 120 & 73.6 \\
\hline & Repair only & 20 & 12.3 \\
\hline & Repair with sterilization & 20 & 12.3 \\
\hline \multirow[t]{2}{*}{ Surgeon } & Obstetrician & 100 & 61.3 \\
\hline & Resident/registrar & 63 & 38.7 \\
\hline
\end{tabular}

Subtotal hysterectomy was the most common surgical intervention (73.6\%). Rent repair with bilateral tubal ligation was done in $12.3 \%$ and rent repair only in $12.3 \%$ of cases (Table 4 ). Most operations were done by obstetricians (61.3\%). Of all patients, $21.5 \%$ the diagnosis of uterine rupture was correctly made at the referring institution whereas majority of the cases were diagnosed on admission at Muhimbili National Hospital (68.7\%) and in some (8\%) diagnoses were made intraoperatively (Table 4). 


\section{Discussion}

The incidence of ruptured uterus at $\mathrm{MNH}$ has not changed over time and it has remained high despite a significant drop in the number of deliveries and rise in the caesarean section rate. The number of deliveries has dropped from 12,242 in 2003 to 9,492 in 2009.

The incidence in this study is lower than that found in studies in Ethiopia, Pakistan (1:100 deliveries) and Nigeria (1:273) (Amanel \& Mengiste, 2002; Padhye, 2005; Ezechi et al., 2004) However, it is higher when compared to studies done in developed countries (Guise et al., 2004; Kaczmarczyk et al., 2007). The difference could be explained by differences in delivery service coverage, accessibility of the facilities as well as availability of skilled personnel and medical supplies.

Ruptured uterus occurred much more frequently in unscarred uteri following obstructed labour as has been found in some studies from other low income countries (Mulumba, 1996; Miller et al., 1997). However, the frequency of rupture of scarred uterus observed in this study is of concern since rupture of scared uterus was approximately as higher as that of unscarred uterus. This might be due to inadequate monitoring of patient on trial of scar, delayed referral, and delayed operative intervention due to long queue in theatre. The majority of scar ruptures occur in the absence of macroscopic or clinical signs of blood loss. Contrarily, major haemorrhage, ICU admission and hysterectomy occur more frequent with rupture of the unscarred uterus (Ofir et al., 2004). This is probably caused by a much lower index of suspicion in an unscarred uterus which may add to a delay in diagnosing uterine rupture. There may also be reduced blood loss in rupture of scar tissue compared to unscarred uterine rupture (Lydon-Rochelle et al., 2001). Major obstetric haemorrhage was the most common presenting symptom of uterine rupture in this study; therefore, differential diagnosis of major obstetric haemorrhage should always include uterine rupture. All patients required blood transfusion, this fact indicates how comprehensive emergence obstetric care is necessary to save life. The hospitals need for blood at Muhimbili National Hospital is always overwhelmed by many patients requiring blood transfusion, therefore, in emergence situation like ruptured uterus there may be less blood than required for resuscitation of the patient.

In this study rupture of the gravid uterus in primigravid occurred in $8.6 \%$ of the cases. This is higher when compared to other studies (London, 2006). All primgravida with ruptured uterus had their labour augmented with pitocin or misoprostol. This unusually high number of ruptured uterus in primigravida cannot be entirely tied up to use of oxytocin and misoprostol since local herbs with oxitocic effects are widely used by local communities in Tanzania. Furthermore, some scaring of the uterus like those happening on unsafe abortions are rarely reported. In Tanzania 95\% of all women attends ante-natal care clinics at least once as evidenced in this study, therefore there was an opportunity to plan for place, timing and mode of delivery although this has been questioned in the literature.

We found an increased risk of uterine rupture after induction of labour as has been reported in other studies. Heckel et al. (1993) reported that induction with prostaglandins confers the highest risk of uterine rupture. Therefore careful selection of cases and supervised use of these drugs is necessary. Furthermore, proper use of parthogram for monitoring patients in labour could help in early diagnosis of poor progress of labour even before obstructed labour as well as timely surgical intervention. As has been indicated in this study majority of patients were referred from the district hospitals. Strengthening of these hospitals in terms of staffing and equipment will help in the management of patients 
to reduce the burden to Muhimbili National Hospital. A delay in referral has been cited as one of the cause of adverse maternal and perinatal outcome among patients referred to MNH (Kidanto et al., 2009).

In the present study, ruptured uterus accounted for $6.6 \%$ of all maternal deaths. However, the case fatality rate appears to be low when compared to studies done in Nigeria and Zambia where case fatality rates were found to range between 18-44\% (Mulumba, 1996; Ezechi et al., 2004). Findings from our study are comparable to those done in Ethiopia (Amanel, 2002), where the case fatality rate was $11.1 \%$. The differences in maternal outcome reflect differences in the quality of maternal health care provided in different countries.

The high perinatal mortality rate in this study is comparable to other studies elsewhere (Yap et al., 2001; Kieser \& Baskett, 2002; Kwee et al., 2007). Foetal outcome in ruptured uterus is determined by the time taken between diagnosis and operation, presence of expertise as well as neonatal care. The high case fatality rate in our study reflects delays in diagnosis, referrals and intervention. $\mathrm{MNH}$ is the only public referral tertiary hospital in Dar es Salaam, the three municipal hospitals do not have effective round the clock comprehensive emergency obstetric care, and therefore, most cases which needed emergency operative delivery were referred to $\mathrm{MNH}$ which resulted to long queue for operation. During the same time there was major renovation of the obstetric theatre and only one operating room was available. This might also have contributed to the delays in care. However, the fact that majority of cases were referred from municipal hospitals and only few were even suspected or diagnosed to have ruptured uterus shows that there is a need to streamline the referral system to avoid delays. Furthermore, it is also important to improve comprehensive emergence obstetric care in these hospitals so that interventions could be done right there to avoid unnecessary delays.

The type of surgical intervention in ruptured uterus depends upon the site, extent as well as the experience of the surgeon. In this study subtotal hysterectomy was the most preferred procedure possibly because ruptured uterus is an obstetric emergency that requires quick response to arrest bleeding and subtotal hysterectomy provides a quick means to achieve homeostasis. Nearly $90 \%$ of patients in our study lost their reproductive and/or menstrual function following surgical interventions. Rupture of the uterus therefore has a grave socio-cultural implication especially in societies, where reproduction is considered the very essence of womanhood. Repair of uterine rupture may be a good alternative for hysterectomy, especially when the woman has few or no living children. However it carries a very high risk of rupture in the next pregnancy (Yap et al., 2001).

The main limitations of this study is that, being a hospital based study it might be not representing what is happening in the community at large. Furthermore, we were not able to include all events of what happened in the referring institutions due to poor documentation. As majority of the patients were referred from other hospitals, lack of information from them may hinder planning on prevention of ruptured uterus. However, improved quality of antenatal care coupled with proper monitoring during labour at $\mathrm{MNH}$ and the referring health facilities in Dar es Salaam and neighbouring regions will have a significant contribution towards the reduction of the incidence of uterine rupture and its associate complications.

In conclusion, the incidence of ruptured uterus at Muhimbili National Hospital is high and contributes significantly to both maternal and foetal morbidity and mortality. Proper monitoring of labour both in the referring facilities and at $\mathrm{MNH}$ and improvement of 
comprehensive emergence obstetric care in all levels will contribute to the reduction of these morbidities and mortalities related to ruptured uterus.

\section{Competing interests}

The authors declare that they have no competing interests.

\section{Authors' contributions}

HLK participated in design of the study, provided background knowledge to the data analysis and interpretation and provided feedback on earlier drafts of the manuscript. IM participated in design of the study, carried out the data collection. JR participated in the analyses and reviewed the manuscript.

\section{References}

Amanel, G. \& Mengiste, M.M. (2002) Ruptured uterus-eight years retrospective analysis of causes and management outcomes at Digrat Hospital Ethiopia. Ethiopian Journal of Health and Development 16, 241-245.

Ezechi, O.C., Mabeye, P. \& Obiesie, L.O. (2004) Ruptured uterus in southern Nigeria: Reapraisal. Singapore Medical Journal 4593, 113-116.

Guise, J.M., McDonagh, M.S., Osterweil, P., Nygren, P., Chan, B.K. \& Helfand, M. (2004) Systematic review of the incidence and consequences of uterine rupture in women with previous caesarean section. BMJ 329, 19-25.

Heckel, S., Ohl, J. \& Dellenbach, P. (1993) Rupture of an unscarred uterus at full term after an intracervical application of dinoprostone (Prepidil) gel. Revue Francaise de Gynecologie et D Obstetrique 88,162-164.

Hofmeyr, G.J., Say, L. \& Gulmezoglu, A.M. (2005) WHO systematic review of maternal mortality and morbidity: the prevalence of uterine rupture. BJOG 112, 1221-1228.

Kaczmarczyk, M., Sparén, P., Terry, P. \& Cnattingius, S. (2007) Risk factors for uterine rupture and neonatal consequences of uterine rupture: a population-based study of successive pregnancies in Sweden. BJOG 114, 1208-1214.

Kidanto, H.L., Mogren, I., Van Rosemalin, J., Thomas, A., Massawe, S.N., Nystrom, L. \& Lindmark, G. (2009) Introduction of qualitative perinatal audit at Muhimbili National Hospital, Dar es Salaam, Tanzania. BMC Pregnancy and Childbirth 9:45.

Kieser, K.E. \& Baskett, T.F. (2002) A 10-year population-based study of uterine rupture. Obstetrics \& Gynecology 100, 749-753.

Kwee, A., Bots, M.L., Visser, G.H. \& Bruinse, H.W. (2007) Obstetric management and outcome of pregnancy in women with a history of caesarean section in the Netherlands. European Journal of Obstetrics \& Gynecology and Reproductive Biology132, 171-176.

London, M.B. (2001) Uterine rupture in primigravid women. Obstetrics \& Gynecology 108, 709-710.

Lydon-Rochelle, M., Holt, V.L., Easterling, T.R. \& Martin, D.P. (2001) Risk of uterine rupture during labor among women with a prior caesarean delivery. New England Journal of Medicine 345, 3-6. 
Miller, D.A., Goodwin, T.M., Gherman, R.B. \& Paul, R.H. (1997) Intrapartum rupture of the unscarred uterus. Obstetrics \& Gynecology 89, 671-673.

Mishra, S.K., Morris, N. \& Uprety, D.K. (2006) Uterine rupture: Preventable obstetric tragedies? Australian and New Zealand Journal of Obstetrics and Gynecology 46, 541-545.

Mulumba, N. (1996) Rupture of the uterus: a review of 32 cases in a General Hospital in Zambia. BMJ 312, 1204-1205.

Ofir, K., Sheiner, E., Levy, A., Katz, M. \& Mazor, M. (2004) Uterine rupture: differences between a scarred and an unscarred uterus. American Journal of Obstetrics and Gynecology 191, 425-429.

Padhye, S.M. (2005) Rupture of pregnant uterus- a 20 years review. Kathmandu University Medical Journal 3, 234-238.

Yap, O.W., Kim, E.S. \& Laros, R.K. Jr. (2001) Maternal and neonatal outcomes after uterine rupture in labor. American Journal of Obstetrics and Gynecology 184, 1576-1581. 